\title{
Hands-on: Elevating the Quality of Classroom Participation through Challenge-Action-Result Technique in English-Medium Instruction to Medical Arab Students
}

\author{
Mohammed Abdulgalil Abugohar,", Baderaddin Yassin ${ }^{2}$ \\ ${ }^{1}$ Department of English Language, Al-Ghad International Colleges for Applied Medical Sciences, Saudi Arabia \\ ${ }^{2}$ English Language Center, Al-Ghad International Colleges for Applied Medical Sciences, Saudi Arabia
}

Received May 27, 2020; Revised July 14, 2020; Accepted July 29, 2020

\section{Cite This Paper in the following Citation Styles}

(a): [1] Mohammed Abdulgalil Abugohar, Baderaddin Yassin, "Hands-on: Elevating the Quality of Classroom Participation through Challenge-Action-Result Technique in English-Medium Instruction to Medical Arab Students," Universal Journal of Educational Research, Vol. 8, No. 9, pp. 4071-4079, 2020. DOI: 10.13189/ujer.2020.080932.

(b): Mohammed Abdulgalil Abugohar, Baderaddin Yassin (2020). Hands-on: Elevating the Quality of Classroom Participation through Challenge-Action-Result Technique in English-Medium Instruction to Medical Arab Students. Universal Journal of Educational Research, 8(9), 4071-4079. DOI: 10.13189/ujer.2020.080932.

Copyright $\bigcirc 2020$ by authors, all rights reserved. Authors agree that this article remains permanently open access under the terms of the Creative Commons Attribution License 4.0 International License

\begin{abstract}
The success essence of language teaching is assessed against its true outcomes. To this end, ESL teachers should effectively exploit all available techniques to help their students master the target language's communicative skills. One proposed technique is to turn the learning environment into a speaking classroom where learners can be actively engaged in interactive communication. As an attempt to do so, this qualitative study explores the potential of classroom teacher-student and student-student interaction using the target language (L2) through the technique of Challenge, Action, and Result (CAR) for fostering university students' classroom communication quality in general, and in-lecture participation and speaking confidence in particular as a part of a whole project that aims at enhancing learners' communicative proficiency. The qualitative data for this study were obtained in the Academic Year 2019/2020 by observing 31 Saudi tertiary students selected purposively to follow up on their language performance and classroom participation. A performance progress record was developed and then implemented after being validated by experts, while an inter rater contributed to ensuring the credibility of the interpretation. The study results unveiled a positive connection between the interaction synergy via the often use of the target language and participants' oral
\end{abstract}

participation, and their speaking confidence. This productive effect resulted in improving the quality of classroom communication level using the CAR technique. In terms of implications, we intended to share our experience based on the research results to draw the attention of those involved in the education process to stress the use of the target language as the sole medium of language classroom interaction through innovative techniques.

Keywords Classroom Interaction, Elevating Participation Quality, Fostering Confidence, CAR Technique, English-Medium Instruction

\section{Introduction}

There is an increasing worldwide demand for highly qualified medical care providers who can keep updated with the brand-new data and information in their career, and who are able to communicate effectively with their international colleagues. This globally admitted need involves mastering communication skills in English as the leading international language, and the status is much more 
pressing for medical majors in the Arab world. To do so, an effective teaching-learning environment should be formulated in a way that provides learners with the opportunity to express themselves in the target language. Consequently, the responsibility to accomplish this set goal has been on the shoulders of language teachers, which makes English-medium instruction a must when designing a curriculum for university learners (Tamtam et al., 2012), specifically for medical-majoring students. Classroom interaction using the target language cannot be devalued since the main target of English language teaching (ELT) is to enable learners to adequately express themselves in the target language and to master English language communicative skills. Communicative skills are the different media through which a person can express himself, contact with others, and send/receive and interpret a message. Nonetheless, observation has revealed that most ESL teachers tend to take the easy way of mediating the learners' native language (L1) in delivering the target language (L2). In English language teaching (ELT), teachers, and consequently students, mainly use L1 and insufficiently use the target language during in-class activities and practices where most practices neglect to no small extent speaking and communicating in the target language as a channel for classroom interaction.

Teaching English in a non-native environment that lacks practices beyond the walls of classroom is a hard task for both teachers and learners. However, some teachers tend to implement classical teaching methods, during which students sit, listen, and wait for the teacher to explain everything related to class (Yassin, 2015). Therefore, some if not most practices of English language courses are delivered in the native language instead of the target language even though the materials are in English; elaboration and discussions are mainly native-language based following the grammar-translation method despite the refusal of most teachers to admit so. The majority of tertiary students rely on L1 to understand L2 target materials. Few lessons are conducted using the target language in its full aspect.

Brown (2016) states that interaction is the basis of L2 learning, through which students are engaged both in enhancing their communicative abilities and in socially constructing their identities through collaboration and negotiation. Fahad (2012) asserts that interacting in the target language and mastering communicative skills have always been a benchmark of ELT all over the world. One of the most challenging features of English for students is to actively communicate in the target language. However, true communication in English is often neglected by English teachers in general, and by some lecturers in higher education as well. It has been conclusively stated in literature that in settings where teachers tended to have much control of the class, giving themselves the big chunk of communication and where the dominant talk time was for teachers (TTT), learners were mostly passive lacking communication skills. On the contrary, in a student-centered environment, students were more engaged in conversations and classroom discussions, making them more confident speakers and active participants. This is in support of the article of faith that claims that teacher's over-talk weakens learners' interaction and hence influences their communication and participation negatively. Exactly just as the issue of learning how to swim that can only be achieved through practice and drilling, the only way for ESL/EFL learners to master the target language is to interact in English. Therefore, this study sheds light on the importance of using English as a prescribed instruction and interaction medium in language classrooms.

In summary, one of the main roles placed on language instructors is to provide samples of the target language for learners. Language students are in crucial need of encountering L2 to acquire or learn it (Cook, 2006). The argument suggests that the teacher can maximize the provision of useful L2 examples by avoiding the L1 since the primary means of mediation is verbal interaction using language (Ellis, 2012). Since this study highlights the value of using English inside classrooms as the medium of class interaction and communication, it is supposed to be of great value for language teachers as it sheds much light on a teaching medium that can make learning more effective and create a semi-native environment rich in practices and activities in the target language for the sake of improving college students' participation.

\section{Literature Review}

Applying the target language in classroom interaction is theoretically based on second language acquisition-learning theories. Interaction has played an important role in SLA theory for several decades (Loewen \& Sato, 2018). A wide range of research has been done concerning using the target language for in-class practices and activities. It has been concluded that the more English-like the teaching-learning environment is, the more active learners become. Vygotsky (1962) argues that children learn through social interaction. Children construct their knowledge through other people; through interaction with adults. In ELT, teachers act as the more knowledgeable others (MKO) together with peer coaching, students work actively to promote their communication in the target language.

Evidently, literature is rich in strong evidence that communicative interaction approaches have been found appropriate methods of teaching English language skills in general, and oral participation in particular (Al-Harbi, 2017). A lot of scholars have advocated using the target language in classrooms as much as possible. Macaro (1997) confirms that language learners are expected to use and respond to the target language and to use their mother 
tongue only when necessary. However, mastering communication and oral skills is not an easy mission for language learners. Moreover, Ohta (2009) clarifies that there is a growing interest among teachers and researchers in comprehending how language enhancement takes place via real-time interaction in classrooms, not in laboratories. Furthermore, using English in classroom interaction at a comprehensible level is expected to result in creating a natural discourse for language practice which is completely consistent with the five hypotheses of the language acquisition (Krashen, 2009; Krashen \& Terrell, 1995), facilitating opportunities for learners to interact through conversation in the classroom; this interaction is essential for learning (Dickson, 1996). In brief, the monolingual approach is advocated by Krashen's (2009) theory of second language learning (SLL) which assumes that when learning second or foreign languages (L2), students follow the same route as they do when they acquire their mother tongue, and hence the use of the mother tongue (L1) in the learning process should be minimized to sustain the accomplishment of language learning objectives.

One mixed-methods study conducted by Alshehri (2017) explored the frequency and functions of using L1 in EFL classes. She employed two instruments- a questionnaire and follow-up interviews to collect data from EFL teachers of the preparatory year at a state university in Saudi Arabia. For the Questionnaire, data were obtained from $104 \mathrm{EFL}$ teachers, and semi-structured interviews were carried out with five teachers to gain a full understanding of their attitudes towards using L1 in EFL classes. Alshehri's (2017) findings showed that the EFL teachers use L1 to some extent to serve certain pedagogical functions, such as explaining vocabulary.

Besides, Yassin (2015) investigated the challenges encountered by undergraduate Jordanian students on learning English as a Foreign language and concluded with highlighting five challenges which were: the limited exposure to L2, classical teaching methods that were not up to the bar of professionalism and commitment, frequent use of L1 as a medium of classroom communication, lack of accommodations in language classrooms, and most learners' refrainment from participating and asking questions in the target language during language lectures.

Further, Jia (2013) concluded that classroom interaction is vital to promote the effect of language classroom teaching and learning. He stated that there is a lack of interaction in English language classrooms. He also revealed that most college EFL learners in China sit looking straight ahead and use minimal facial expressions, gestures, and verbal utterances; some student participants seldom ask questions, while others keep their heads down and remain silent when asked questions or assigned to group work.

Moreover, Fahad (2012) concluded that the level of EFL learners in Iraq has always been unsatisfactory because of the apparent lack of exposure to the target language in Iraqi classrooms, and the focus has always been on the grammar and form. Further, Khati (2011) argued that no studies recommend the excessive use of mother tongue in the classroom since this tendency hinders exposure to the target language. He criticized the overuse of mother tongue in language classes that resulted in minimizing the students' exposure to English. In his paper, Guilloteaux (2008) found out that classroom management in language teaching can be broadly depicted in which language teachers adhere to creating and maintaining a classroom environment that can enhance optimal learning of the target language while promoting the development of student self-control. Therefore, managing a language classroom requires overseeing all classroom activities, including language learning activities, social interactions, and student performance.

In brief, it can be stated, referring to the considerable amount of literature in hand as well as the researchers' experience, that most EFL/ESL teachers overuse mother tongue (L1) in the delivery of the target material of L2. This is believed to result in a negative impact on language learners' participation and interaction in the target language.

\section{L1 or L2 Controversy}

There has been a lot of debate on which language to use as a medium of instruction and classroom interaction- L1 or L2. Most scholars advocate that L2 is the channel to use to maintain effective engagement and enhancement of the target language. They insist that using learners' first language (L1) must be widely avoided in English as a foreign language (EFL) and English as a second language (ESL) classes (Cook, 2001; Dickson, 1996; Khati, 2011; Littlewood \& Yu, 2011; Macaro, 1997; Ribas, 2010). Others tend to tolerate the use of L1 to help learners comparatively realize the characteristics of L2 during which L1 can aid the learning process of L2 (Atkinson, 1993; Aurebach, 1993; Qadumi, 2007; Schweers, 1999). In the reconciliation of the controversy arisen, Millous (2003) argues that there is no formula to fit all teachers in all teaching contexts all of the time. It depends mainly on the properties of the target learners and the nature of the target material.

Nevertheless, since college adult learners are the target population for the current research, it is believed that L2 should be used as the main and only medium of classroom interaction and communication to help attain the desired objectives of boosting classroom participation.

\section{Research Methodology}

In this research, we tried to explore how English-medium instruction (EMI) through the technique of Challenge, Action, and Result (CAR) can help in 
creating a positive change in participants' performance, which can be offered as a solution to one of the problems confronting EFL teachers; which is the passive-receptive students during language classes. The methodology applied in this case-study research was driven by one main question: How does English-medium instruction help elevate the quality of students' in-class participation through CAR technique?

To this purpose, we followed up 31 Saudi students at the university level of education, all were male students. The study was carried out in the first semester of the Academic Year 2019/2020. The study population was enrolled in an intensive language course during which they were taught English for 20 hours per week, and they were selected for their availability and reachability for the researchers. We tracked the progress of the participants over a period of four weeks for a total of 80 hours in terms of their participation in classroom activities as well as their oral confidence and interaction. A 3-step CAR technique of 'Challenge,' 'Action,' and 'Result' was applied, as depicted in Figure 1.

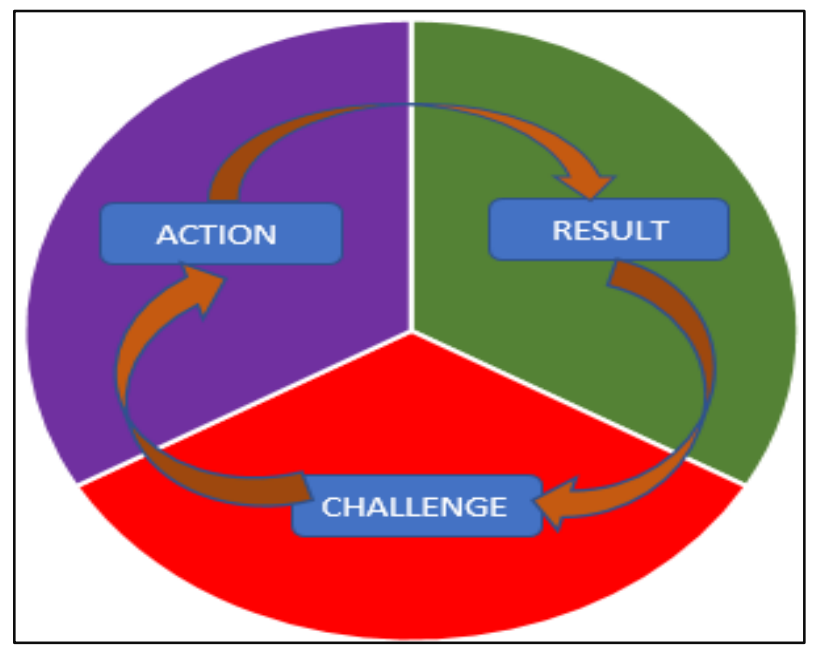

Figure 1. CAR Technique

As shown in Figure 1, a series of a challenge-Action-Result technique was set to implement in English-medium instruction. Learners' abilities were challenged when using only the target language as the sole medium of classroom instruction and communication. This technique was to force students to take actions and start using L2 while struggling to comprehend and respond to their teacher and counterparts. Then, the results were recorded to be analyzed later.

We adopted the qualitative research approach in conducting the present study for which the data were collected through close observation of classroom practices and interaction to capture comprehensive understanding based on an inductive tracing of learners' improvement, attempting to find a solution to help in tapping on the issue of the low level of participation found in language classes. Then, the data obtained were encoded and analyzed to be thematically interpreted later. This was done to boost students' level of interaction, confidence, enthusiasm, and participation progress in the target language. In terms of the transformability of the research findings, it should be limited to college students. Moreover, the research inductively explored only in-class real-time participation and interaction; out-class activities were not included.

\section{Data Collection \& Analysis Tools}

In terms of instrumentation, the main instrument used for collecting the data was a note-taking diary using a follow-up checklist and progress report. First, the follow-up checklist was self-developed by the researchers. The data collection tools were used as a record to track the daily progress of participants in English language classrooms.

Then, a group of 31 students was followed up to collect the data. To ensure the credibility of the analyses and the findings, an ELT academician has acted as an intercoder for the qualitative data obtained during the performance observations.

The tools used to collect data were assessed regularly to ensure its comprehensiveness. The checklist items were developed and validated. The items covered classroom practices and interactions. The observation record consisted of four main categories- interaction, confidence, enthusiasm, and participation progress. Each category was divided into sub-divisions. First, the level of interaction was divided into active and passive. Second, the confidence domain consisted of two columns- confident and hesitant. For the third criterion, enthusiasm was to state whether learners were positively enthusiastic or shy and anxious, avoiding taking part. Fourth, students' real progress was reported according to the quality of learners' participation in each week compared to the whole period. The data obtained were first listed hourly, week by week for four weeks. The data were then classified in terms of codes. After that, thematic analysis was applied to scrutinize the data obtained. The concluded interpretation was encoded in the shape of percentages for the four criteria set.

Classroom interaction was tracked both quantitatively and qualitatively; however, the analysis depended more on quality than quantity. The quantitative data were only used to help support the qualitative data, which were our main concern of this research. The effectiveness of participation was assessed in terms of positive interactive roles played by students during classroom discussions and practices. For confidence, it was evaluated based on the voice tone and the variety of fluent and smooth expressions used by learners during the teaching and learning sessions. Then, the enthusiasm of participants was measured by body language, gestures, and facial expressions. Finally, language students' progress was recorded according to how more interactive and effective each class was than the 
previous session, summing up the average of the previous three main criteria.

\section{Research Results}

The study explored how far using English, being the target language (L2) as the only channel for language classroom communication, can maintain a good quality of learners' participation. The main target of all language learners is to use and master communication and interaction in that target language; however, learning a second or foreign language in educational institutions has traditionally been weighted in terms of listening, reading and writing aspects than speaking in its spontaneous natural features (Starkey, 2012). The issue is that most practices focus much more on the quantity of participation, not the quality. Some just consent to see students chorally taking part in in-class activities. Nonetheless, this research shifts to the dimension of participation quality from four central angles, as stated earlier. The data gained in terms of interaction, confidence, enthusiasm, and progress are analyzed below.

\section{Classroom Interaction}

Language Learners' interaction was recorded for four weeks ( 80 hours) to explore in which direction it was going on. Students' interaction was recorded in the checklist regarding the number of interactions and the number of participants as well as the quality of responses and interaction whether active or passive, and also the type of interaction- student-to-student, student-to-teacher, student-to-group, group-to-group, and group-to-teacher. Then, the average percentage was calculated. Figure 2 visualizes the data obtained for the quality of participation.

The bar chart in Figure 2 presents the data collected in terms of class interaction. Active roles played by students during the 20-hour teaching sessions per week were recorded for each one of the four weeks. It was found that active responses and discussions of participants were estimated as being $(20.4 \%)$ in the first week; while passive learners' participation was encoded higher than the active ones at $(79.6 \%)$. Then, interaction in the second week was calculated at $(43.1 \%)$ for being active and $(56.9 \%)$ for being passive. After that, it was (79.7\%) and (83.7\%) for active roles during the third and fourth weeks, respectively. On the other hand, passive participation was assessed as being $(20.3 \%)$ and $(16.3 \%)$ for the third and fourth weeks, respectively.

\section{Learners' Confidence}

Students' confidence while participating was checked regularly over the assigned period of four weeks. The domain of confidence was evaluated based on learners' voice tone, fluency, speed, and smoothness of oral discussion and responses of participants during language classroom. When fulfilling the previous criteria, a participant was labeled as 'confident'; while being considered a 'hesitant' on failing to do so. The record was kept for every hour, and then the average was computed for the whole week of 20 hours. After that, the four weeks of 80 hours for classroom interaction were calculated comparing the four weeks to each other.

As shown in Figure 3, learners' confidence was increasing at varying rates. In the first week, confidence started at a very low level (15.7\%), then went up to $(20.9 \%)$ in the second week, $(41.5 \%)$ in the third week, and ended up high at $(85.2 \%)$ in the fourth week. On the contrary, participants' hesitant behavior that we traced on responding to classroom communication was digitally encoded as $(84.3 \%)$ in Week $1,(79.1 \%)$ in Week $2,(58.5 \%)$ in Week 3, and (14.8\%) in Week 4.

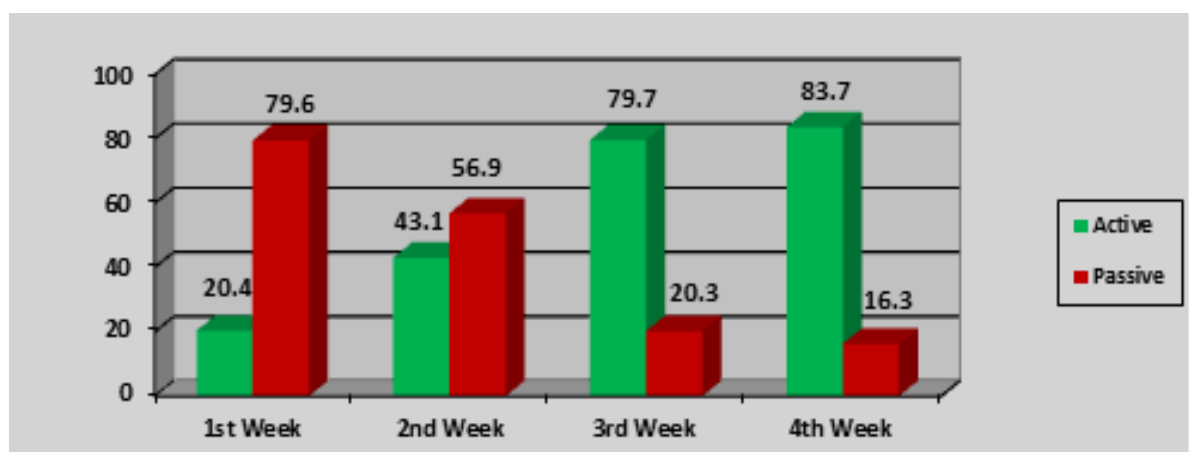

Figure 2. Classroom Interaction 


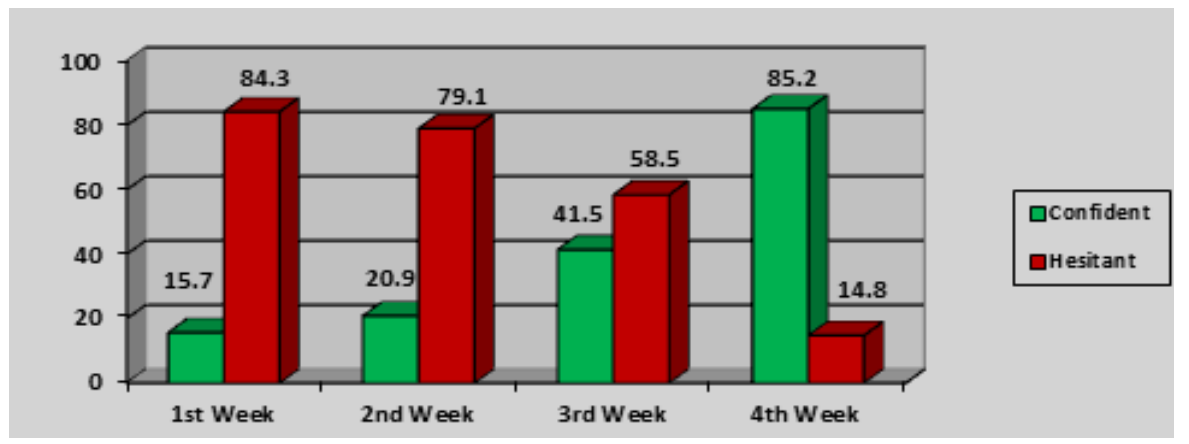

Figure 3. Learners' Confidence

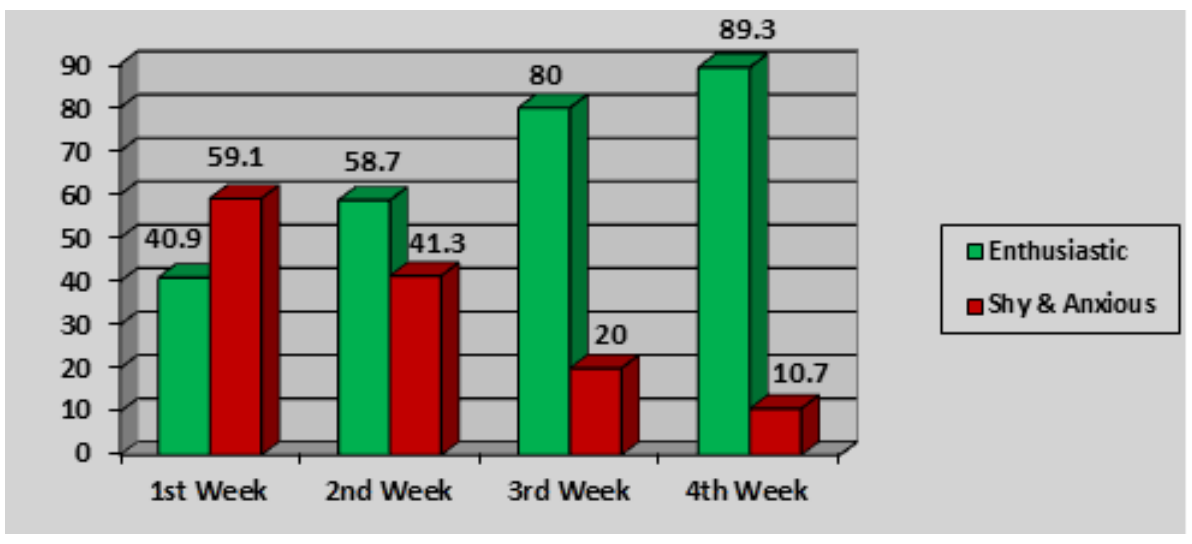

Figure 4. Learners' Enthusiasm

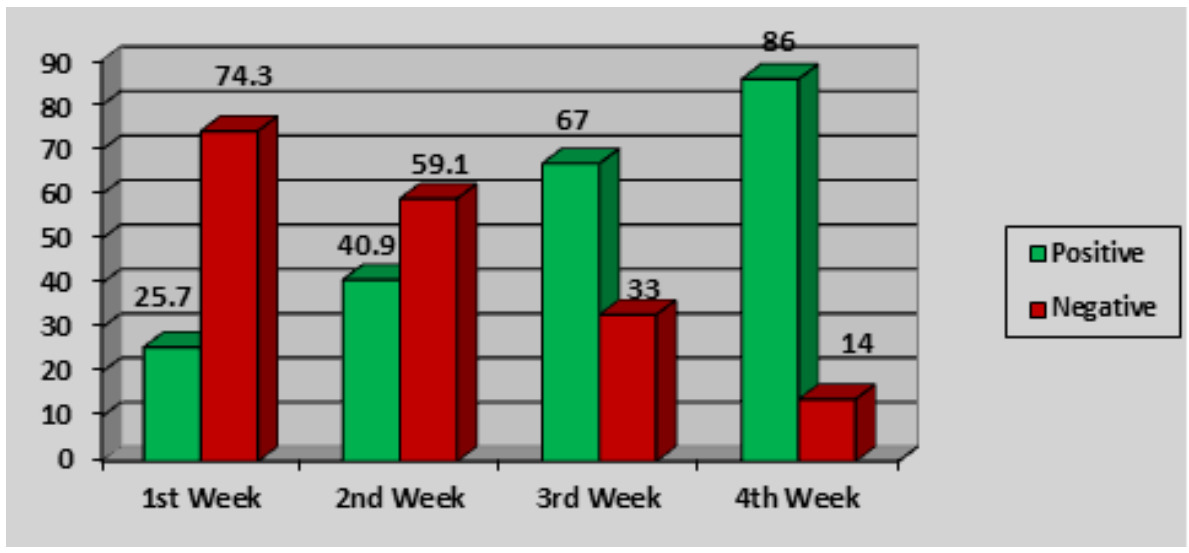

Figure 5. Participation Progress

\section{Participants' Enthusiasm}

The enthusiasm level of learners was interpreted according to the willingness of students to answer, participate, discuss, and negotiate in-class activities. This willingness dwelled in the number of learners raising their hands to take part, their facial expressions of satisfaction after giving correct responses, and the whole class on-going positive atmosphere. These qualities were coded and then thematically analyzed to encode the qualitative data gathered, as charted in Figure 4.

Data shown in Figure 4 revealed that learners' enthusiasm as we elicited during the language class participation was increasing from $(40.9 \%)$ in the first week up to $(89.3 \%)$ in the last week of the target study duration, unlike the average of shy and anxious responses which started at $(59.1 \%)$ in Week 1 and dropped to only $(10.7 \%)$ at the end of Week 4.

\section{Progress of Participation}

The overall classroom participation progress was concluded by calculating the average of the previous three domains of interaction, confidence, and enthusiasm during each week of the four ones to identify the quality of real progress that participants could achieve in terms of 
effective class participation over the 80 -hour delivery of language teaching.

Based on the data gleaned, as shown in Figure 5, effective participation progress of the target language classroom shifted at a high rate from $(25.7 \%)$ in week 1 , $(40.9 \%)$ in week 2, $(67 \%)$ in Week 3 to $(86 \%)$ in Week 4; while decreasing dramatically in terms of ineffective negative participation from $(74.3 \%)$ in the first week, $(59.1 \%)$ in the second week, $(33 \%)$ in the third week to $(14 \%)$ in the last week.

\section{Discussion}

Most observed tertiary students were previously assessed as lacking true interaction and communication in English, which resulted in a low level of learners' participation in language classes. However, when adhering to using the target language for classroom interaction, it remarkably yielded a positive interaction, actively increasing learners' participation.

Firstly, using the target language (L2), from the angle of interaction, was low in the first week at $(20.4 \%)$ which might have resulted from the shock of students when finding themselves surrounded by English all the time within the language classroom until they gradually got used to using English in classroom communication. This ice was next broken during the following weeks, shifting to (43.1\%), then increased at the highest leap of $(79.7 \%)$, and finally scored at $(83.7 \%)$. The third week witnessed the highest point of improvement in participants' class interaction.

Secondly, based on the explored data, one of the outcomes of using the target language in classroom instruction is boosting learners' confidence. In terms of confidence, students' participation improved gradually from a shallow rate of $(15.7 \%)$ in the first week to $(20.9 \%)$ in Week 2, then it was elevated in the third week; whereas the enhancement was at its utmost of (85.2\%) in the last week.

For the third criterion of the enthusiasm, we found out that learners' behavior during interaction and participation did not start at a low average like other aspects; however, the most noticeable improvement was in the third week at $(80 \%)$. Enthusiasm elevates motivation, and motivation acts as the amplifier which is responsible for 'why' students decide to do something, 'how long' they are willing to sustain the activity, and 'how hard' they are going to pursue it (Dornyei, 2014). This motivation was deemed the main factor influencing students' perceptions toward the target language in a way that helps them overcome speaking anxiety.

Finally, the real progress in students' classroom participation was computed from the average of the previous three domains of interaction, confidence, and enthusiasm. The elevation in participation that we followed up was steadily increasing at an average of around (20\%) from a week to the following one, reaching an outstanding standard of $(86 \%)$ in Week 4.

Based on the data obtained, it can be concluded that using the target language as the only medium of classroom communication and interaction could significantly create a positive impact on learners' performance in the language classroom regarding classroom interaction, confidence, enthusiasm, and participation progress that are consequently expected to boost learners' oral production. This conclusion was aligned to what stressed by Ellis (2012) that "when anxiety does arise to the use of L2, it seems to be restricted mainly to speaking and listening" (p. 692). Also, the obtained results stress the role played by instructors in helping their students foster their language skills and participation, making the findings consistent with Azmi and Maniam (2015) who asserted that "Evidently if the teachers are able to meet the challenges, educational reform will be easily and successfully achieved." So, it is the role of language teachers to facilitate every single source and channel for the sake of improving their students' performance. Teachers can also utilize interactive smartphone applications to assist them in attaining these objectives (Abugohar, Yunus \& Rashid, 2019a).

Therefore, one of the remedies explored in the present study is the often use of English as the target language in English-medium instruction (EMI) and discussions in L2. In addition, elevating learners' participation was found a pushing-forward factor for fostering students' active and interactive oral communication which was concluded a crucial critical task for second or foreign language learners, which makes this study aligned to Abugohar et al. (2020), Rabab'ah (2005), Rashid et al. (2017), and Yassin (2015). However, this study conclusion is inconsistent with some found literature in terms of the outcomes of English-medium instruction (e.g., Al Zumor, 2019; Joe and Lee, 2013; Sivaraman et al., 2014), who concluded that EMI impacted the acquisition and mastery of disciplinary content negatively; whereas this study supported the positive outcomes of EMI.

During those challenging lecture sessions where we used English as the main language of classroom discussion and instruction, learners tended to progressively be more active and engaged, and their participation became much more obvious to detect. To sum, sticking to using English, the target language, in classroom communication and interaction challenged learners' abilities and resulted in creating a supportive community of practice for language learners, stressing the importance of appropriate participation in relevant speech events in classroom lessons which is central to communicative competence as discussed by (Mitchell, Myles \& Marsden, 2013).

\section{Conclusions}

"Knowledge alone is not enough to prepare students to 
thrive in the world" (Shing \& Rameli, 2020, p.1). Tertiary education in the 21 st century should perfectly blend a necessary combination of knowledge, thinking, innovation skills, media, and real-life experience (Paige, 2009). This research explored one of the factors that could contribute to boosting students' classroom true participation - using the target language (L2) as the channel of classroom interaction. Adhering to this could promote learners' autonomy and motivation in a low-pressure teaching and learning environment, facilitating the opportunity to language students to practice the target language and providing more room for learners to express themselves, increasing the quantity and quality of students talk time (STT). In a nutshell, filling up the teaching and learning environment with the target language in every single corner can maintain escalating classroom communication in L2 through practices and activities.

One of the conclusive outcomes we had during the implementation of English-medium instruction was the regular assessment of the technique used until it took its updated form as graphed in Figure 6.

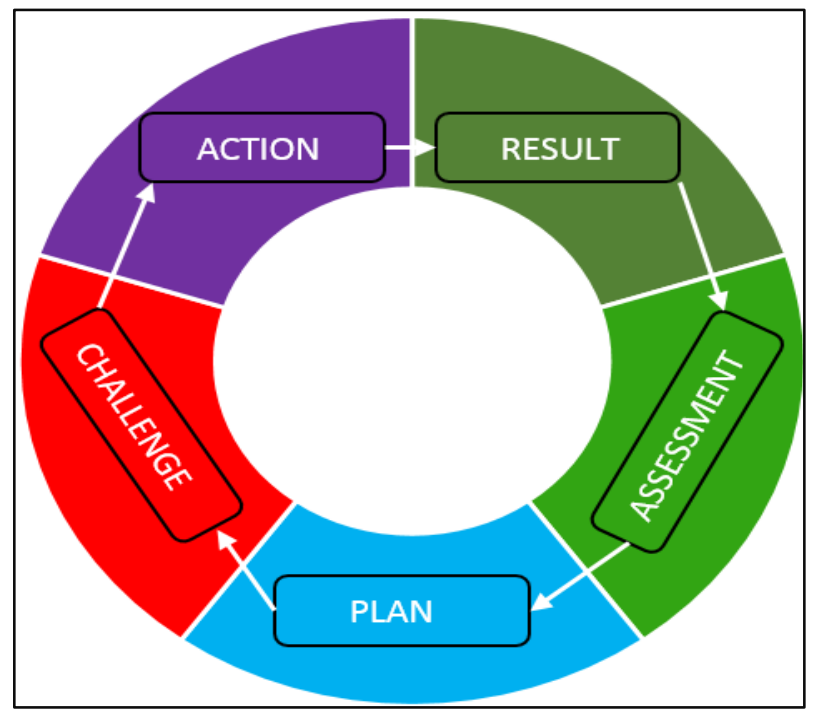

Figure 6. The Updated CAR Technique

As shown in Figure 6, the technique was updated to compose five phases in a circular technique. First, it started with the planning phase, where every instruction session was designed and planned in advance to ensure the maximum effect. Then, the challenge phase comes to impose using English in classroom communication. Next, it comes to learners' actions and reactions which are then reflected in their responses in the result stage. After that, the assessment phase after each session was to evaluate and check how far the technique helped participants foster their classroom communication and speaking confidence in the target language. This was done in a way that each instruction session informed the next scenario in the session following based on the assessment phase.

For implications of the present research, teachers are asked to act as positive role models through using the target language in classroom communication, giving more attention to real-life interaction rather than to the mere abstract instruction. This can also be supported by a variety of activities, role play, speech acts, students' public presentation, technology-based classroom interaction, and handheld technologies (Abugohar et al., 2019b). One last recommendation for teachers of second and foreign languages is to be patient as much as they can till they see their efforts crowned in the shape of getting learners to achieve actual progress in mastering language skills since we did not detect right sufficient outcomes in terms of participation quality till we came to the third week, then students' achievement was at the highest point at the end of our follow-up plan. This means that the language teaching-learning process is accumulatively progressive and takes time, instant results rarely occurs. So, ESL/EFL instructors should never give up trying. They can challenge students' abilities to bring out the best in learners.

\section{REFERENCES}

[1] Abugohar, M., Salheen, D., Yassin, B., Saed, H., \& Yunus, K. (2020). Scaffolding oral fluency mediating the target language in ELT to tertiary-level students: A follow-up scheme. International Journal of Instruction, 13(4).

[2] Abugohar, M., Yunus, K., \& Rashid, R. A. (2019a). Smartphone applications as a teaching technique for enhancing tertiary learners' speaking skills: Perceptions and Practices. International Journal of Emerging Technologies in Learning, 14(9), 74-92. https://doi.org/10.3991/ijet.v14i 09.10375

[3] Abugohar, M., Yunus, K., Raba'ah, G., \& Ahmed, T. A. (2019b). Integrating cloud world synergy in ELT to adults: Perspectives of handheld technologies. International Journal of Interactive Mobile Technologies, 13(10), 150168.

[4] Alshehri, E. (2017). Using learners' first language in EFL classrooms. IAFOR Journal of Language Learning, 3(1), 20-33.

[5] Al Zumor, A. Q. (2019). Challenges of using EMI in teaching and learning of university scientific disciplines: Student's voice. International Journal of Language Education, 3(1), 74-90.

[6] Atkinson, D. (1993). Teaching monolingual classes: Using L1 in the classroom. Harlow: Longman Group Ltd.

[7] Auerbach, E. (1993). Reexamining English only in the ESL classroom. TESOL Quarterly, 27(1), 9-32. https://doi.org/10.2307/3586949

[8] Azmi, N., \& Maniam, M. (2015). Failure of ETeMS: The teaching courseware factor? The Malaysian Online Journal of Educational Science, 1(4), 30-37. Retrieved from http://files.eric.ed.gov/fulltext/EJ1086269.pdf

[9] Brown, D. (2016). The type and linguistic foci of oral 
corrective feedback in the L2 classroom: A meta-analysis. Language Teaching Research, 20, 436-458.

[10] Cook, V. (2006). Using the first language in the classroom. Retrieved fromhttp://homepage.ntlworld.com/vivian.c/Writ ings/Papers/L1 inClass.htm

[11] Dickson, P. (1996). Using the target language; A view from the classroom. Berkshire: The National Foundation for Educational Research.

[12] Dornyei, Z. (2014). Motivation in second language learning. In M. Celce-Murcia, D. Brinton \& M. A. Snow (Eds.), Teaching English as a second or foreign language (pp. 518-531). Boston, MA: Heinle Cengage Learning.

[13] Ellis, R. (2012). The study of second language acquisition. Oxford: Oxford University Press.

[14] Fahad, A. (2012). Enhancing students' communicative skills through classroom interaction in Iraqi EFL classes. University of Thi Qar, College of Education, Department of English.

[15] Guilloteaux, M. J. (2008). Three effective classroom managers: A look inside South Korean EFL classrooms. In T. S. C. Farrell (Ed.), Classroom management (pp. 99-110). Alexandria, VA: TESOL.

[16] Jia, X. (2013). The application of classroom interaction in English lesson. In Proceedings of the International Conference on Education Technology and Information System (ICETIS 2013), 209-212.

[17] Joe, Y., \& Lee, H. (2013). Does English-medium instruction benefit students in EFL contexts? A case of medical students in Korea. Asia-Pacific Education Research Journal, 22(2), 201-207.

[18] Khati, A. R. (2011). When and why of mother tongue use in English classrooms. Journal of NELTA, 16(1-2), 42-51.

[19] Krashen, S. D. (2009). Principles and practice in second language acquisition. Oxford: Pergamon.

[20] Krashen, S. D., \& Terrell, T. D. (1995). The Natural approach \& language acquisition in the language classroom. London: Hall Macmillan.

[21] Loewen, S., \& Sato, M. (2018). Interaction and instructed second language acquisition. Language Teaching, 51(3), 285-329.

[22] Macaro, E. (1997). Target language, collaborative learning and autonomy. Multilingual Matters.

[23] Millous, C. (2003). Using L1 and L2 effectively in the foreign language classroom. MA TESOL Collection. Paper 178 .
[24] Mitchell, R., Myles, F., \& Marsden, E. (2013). Second language learning theories. London: Routledge.

[25] Ohta, A. S. (2009). Rethinking interaction in SLA: Developmentally appropriate assistance in the zone of proximal development and the acquisition of L2 grammar. In J. Lantolf (Ed.), Sociocultural theory and second language learning (pp. 51-78). Oxford: Oxford University Press.

[26] Paige, J. (2009). The 21st century skills movement. Educational Leadership, 9(67), 11-12

[27] Rabab'ah, G. (2005). Communication problems facing Arab learners of English. Journal of Language and Learning, 3(1), 180-197.

[28] Rashid, R., Mohammed, S., Rahman, M., \& Shamsuddin, S. (2017). Developing speaking skills using Virtual Speaking Buddy. International Journal of Emerging Technologies in Learning, 12(5), 195-201. https://doi.org/10.3991/ijet.v12i0 5.6955

[29] Ribas, M. S. (2010). The effects of teacher talk on students' oral productions. (Master Dissertation). TED Masters Degree, UAB.

[30] Sivaraman, I., Al Balushi, A., \& Rao, D. H. (2014). Understanding Omani students' (University) English language problems. International Journal of Sciences: Basic and Applied Research 3(1), 28-35.

[31] Shing, L. S. \& Rameli, M. R. M. (2020). The influence of self-regulation towards academic achievement in English among Malaysian upper primary students. Universal Journal of Educational Research, 8(5A), 1-11. DOI: 10.13189/ujer.2020.081901

[32] Starkey, L. (2012). Teaching and learning in the digital age. London: Routledge.

[33] Schweers, C. W. (1999). Using L1 in the L2 classroom. English Teaching Forum, April-June, 6-13.

[34] Tamtam, A. G., Gallagher, F., Olabi, A. G., \& Naher, S. (2012). Comparative study of the implementation of EMI in Europe, Asia and Africa. Procedia - Social and Behavioral Sciences, 47, 1417 - 1425. https://doi.org/10.1016/j.sbspro. 2012.06.836

[35] Vygotsky, L. (1962). Thought and language. Cambridge: MIT Press.

[36] Yassin, B. (2015). Challenges of teaching English language to English language learners at private universities in Jordan. Arab World English Journal, 6(2), 265-274. 